Supporting Information

\title{
Porphyrin-Based Hydrogen-Bonded Organic Frameworks for the Photocatalytic Degradation of 9,10-Diphenylanthracene
}

Xiao-Tong He, ${ }^{\# \dagger}$ Yang-Hui Luo, ${ }^{\# \star *}$ Zi-Yue Zheng, ${ }^{\dagger}$ Cong Wang, ${ }^{\dagger}$ Jia-Ying Wang, ${ }^{\dagger}$ Dan-Li Hong, $\S^{\S}$ Li-Hai Zhai, $\S$ Li-Hong Guo, ${ }^{b}$ and Bai-Wang Sun* ${ }^{\star}$

† School of Chemistry and Chemical Engineering, Southeast University, Nanjing, 211189, P.R. China. E-mail: peluoyh@sina.com (LYH); chmsunbw@seu.edu.cn (SBW).

§ Lunan Pharmaceutical Co. Ltd., Linyi 276000, Shandong, China.

\# The authors are contributed equally. 
Table S1. Crystal data and structure refinement details for HOFs TCPP2(DMF), TCPP-4(DMF) and TCPP-6(DMF).

\begin{tabular}{|c|c|c|c|}
\hline HOFs & TCPP-2(DMF) & TCPP-4(DMF) & TCPP-6(DMF) \\
\hline Formula & $\mathrm{C}_{60} \mathrm{H}_{66} \mathrm{~N}_{8} \mathrm{O}_{16}$ & $\mathrm{C}_{60} \mathrm{H}_{58} \mathrm{~N}_{8} \mathrm{O}_{12}$ & $\mathrm{C}_{72} \mathrm{H}_{86} \mathrm{~N}_{12} \mathrm{O}_{16}$ \\
\hline Formula weight & 1155.20 & 1083.14 & 1375.52 \\
\hline Crystal system & Triclinic & Triclinic & Monoclinic \\
\hline Space group & $P-1$ & $P-1$ & $P 2{ }_{1} / \mathrm{n}$ \\
\hline $\mathrm{a} / \AA$ & $7.80840(10)$ & $6.4529(2)$ & $6.3338(7)$ \\
\hline $\mathrm{b} / \AA$ & $13.48180(10)$ & $15.6367(5)$ & $37.121(3)$ \\
\hline $\mathrm{c} / \AA$ & $14.56290(10)$ & $17.3229(7)$ & $15.5664(19)$ \\
\hline$\alpha /^{\circ}$ & $81.7810(10)$ & $90.884(3)$ & 90 \\
\hline$\beta /^{\circ}$ & $87.4990(10)$ & $91.325(3)$ & $100.834(13)$ \\
\hline $\mathrm{y}^{\circ}$ & $88.3620(10)$ & $101.792(2)$ & 90 \\
\hline $\mathrm{T} / \mathrm{K}$ & $293(2)$ & $293(2)$ & $293(2)$ \\
\hline$\mu\left(\mathrm{mm}^{-1}\right)$ & 0.771 & 0.612 & 0.749 \\
\hline No. of reflns collected & 6214 & 6977 & 5906 \\
\hline No. of unique reflns & 5423 & 5261 & 4012 \\
\hline No. of params & 392 & 368 & 461 \\
\hline Goodness-of-fit on $F^{2}$ & 1.099 & 1.051 & 1.052 \\
\hline $\mathrm{R}_{1}, \mathrm{wR}_{2}((\mathrm{I}>2 \sigma(\mathrm{I}))$ & $0.0624,0.1974$ & $0.1094,0.3174$ & $0.0824,0.2069$ \\
\hline $\mathrm{R}_{1}, \mathrm{wR}_{2}$ (all data) & $0.0692,0.2087$ & $0.1234,0.3487$ & $0.1156,0.2380$ \\
\hline CCDC No & 1902587 & 1902588 & 1902589 \\
\hline
\end{tabular}


(a)

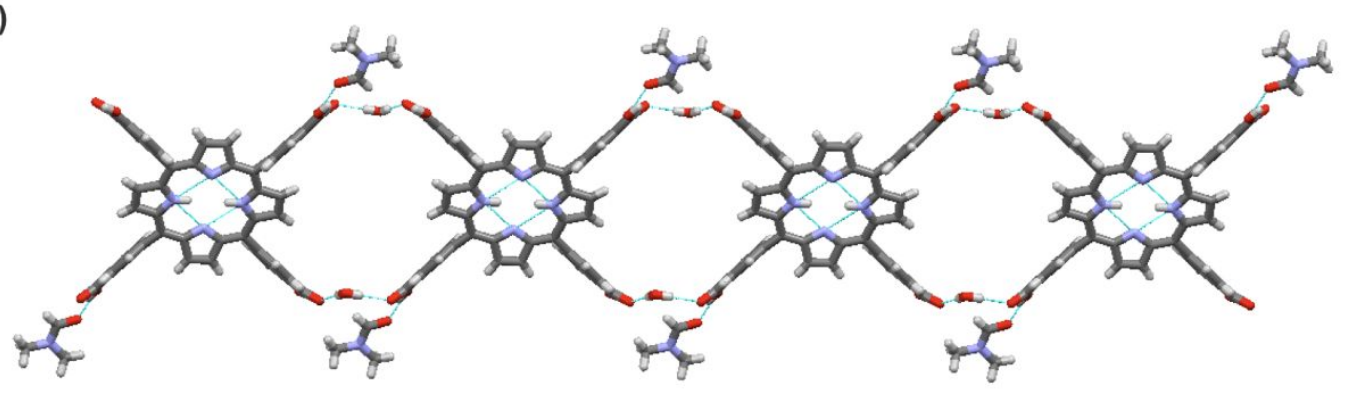

(b)

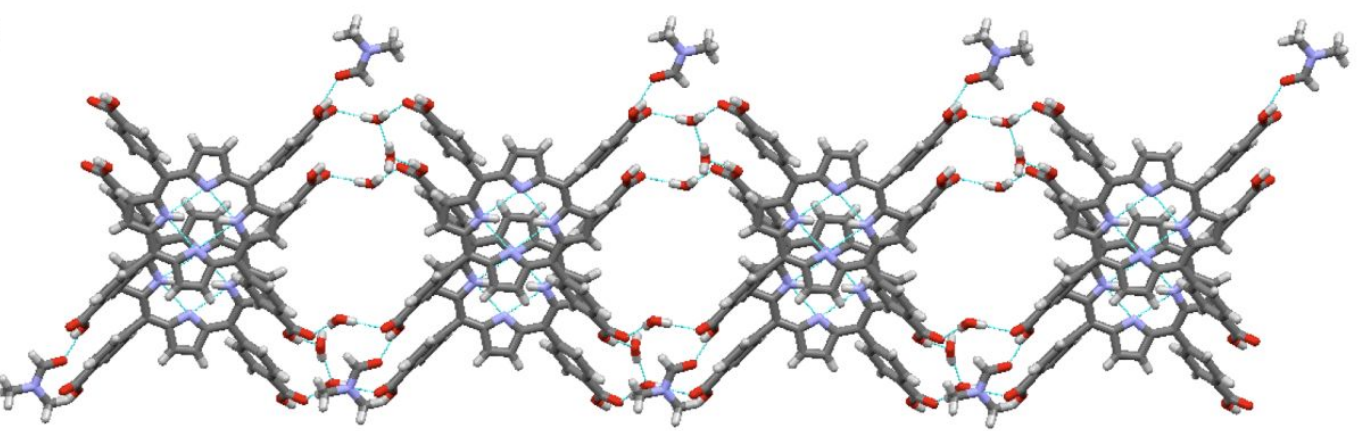

Figure S1 (a) 1D chain and (b) 2D structure of TCPP-2(DMF) mediated by lattice water molecules. 

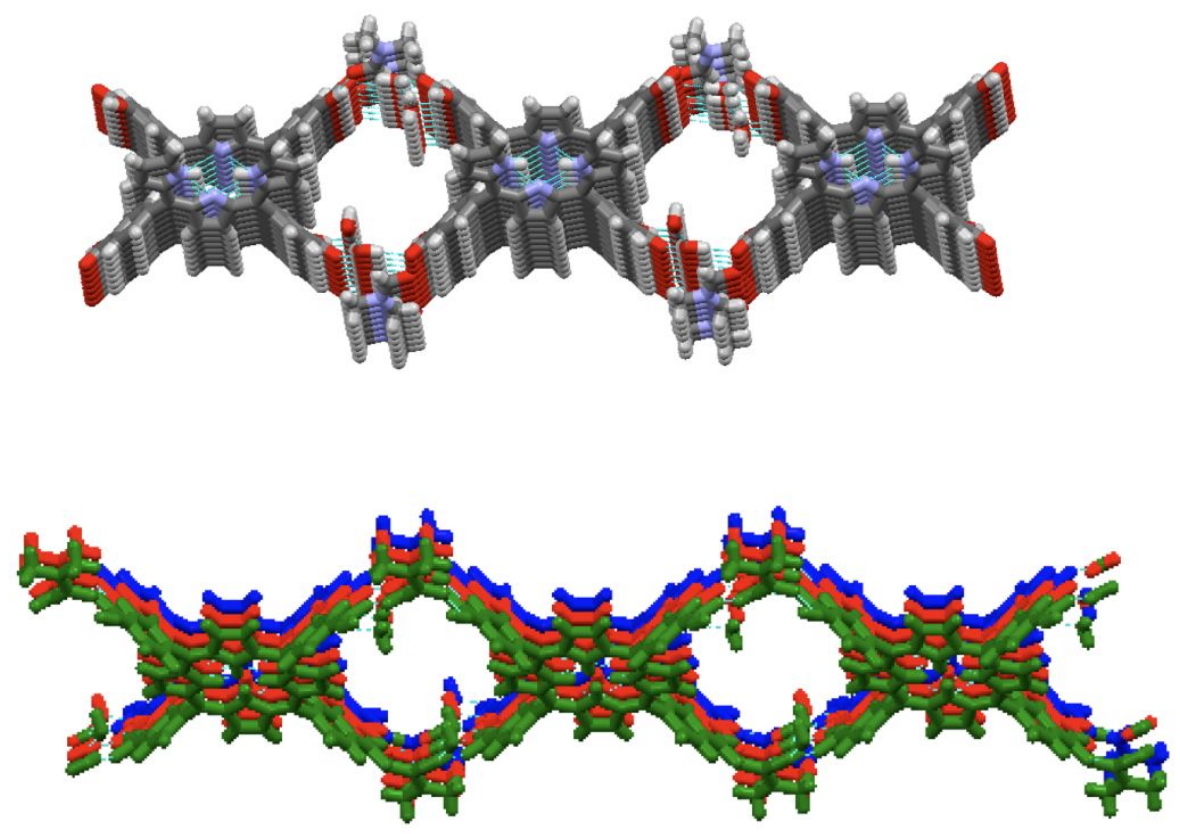

Figure S2 2D motif of TCPP-2(DMF) with ordered 1D channels. 
(a)

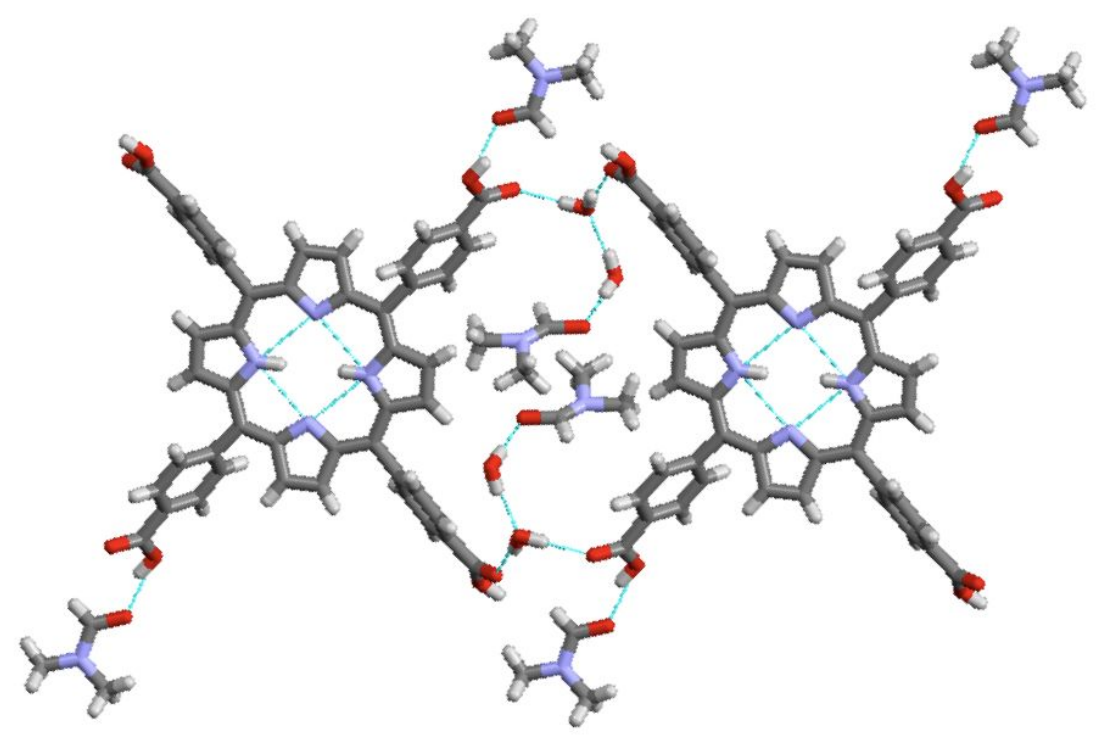

(b)

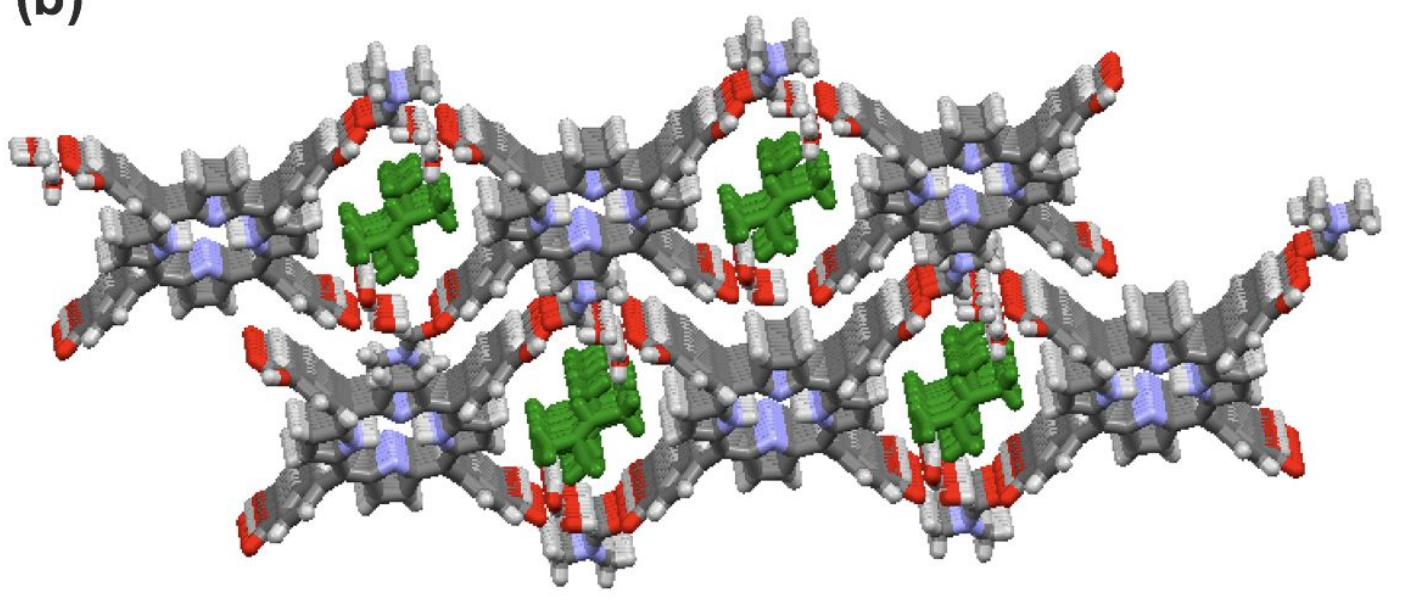

Figure S3 (a) The binding style of DMF molecules located in 1D channels and

(b) 3D porous frameworks of TCPP-2(DMF) with the 1D channels occupied by

DMF molecules (in green color). 


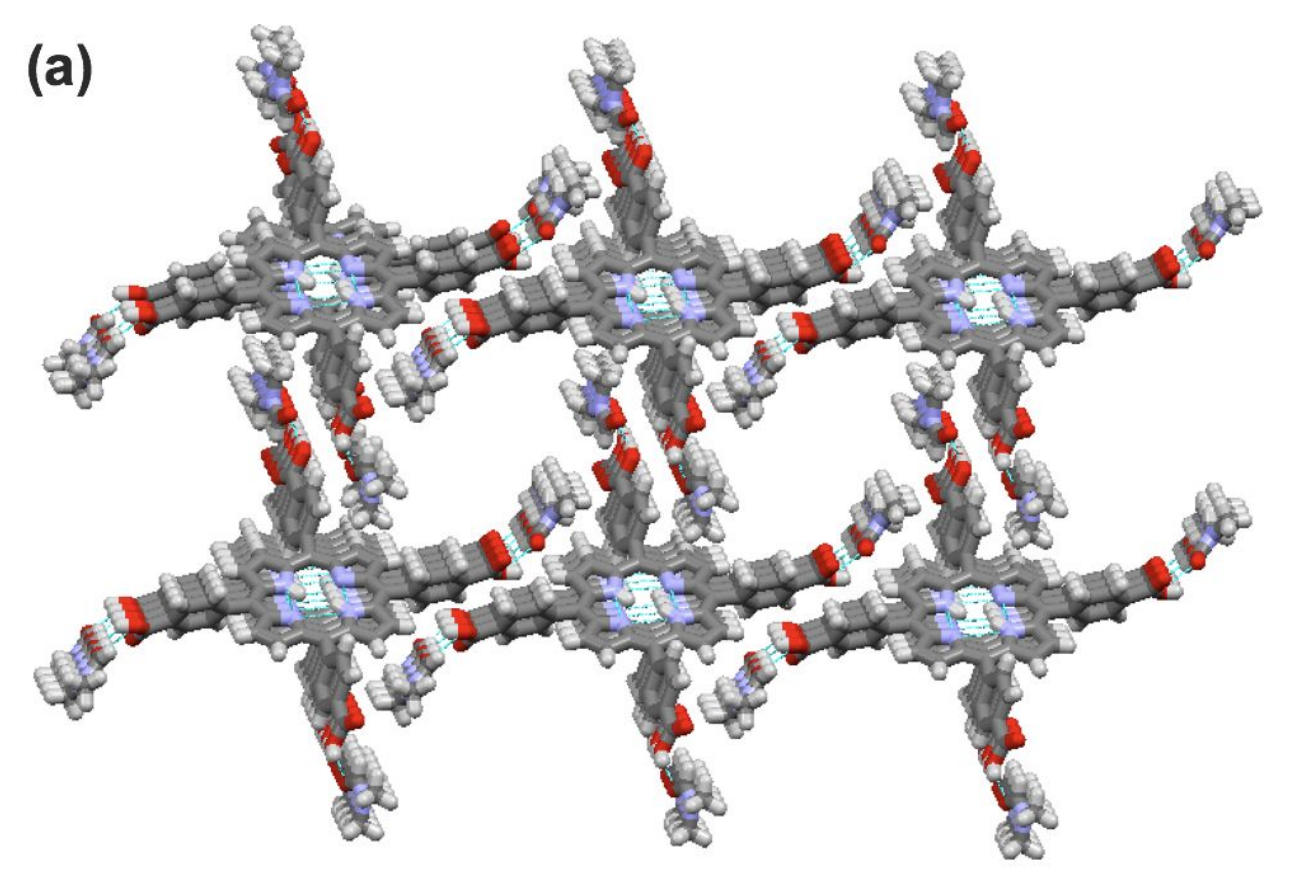

(b)

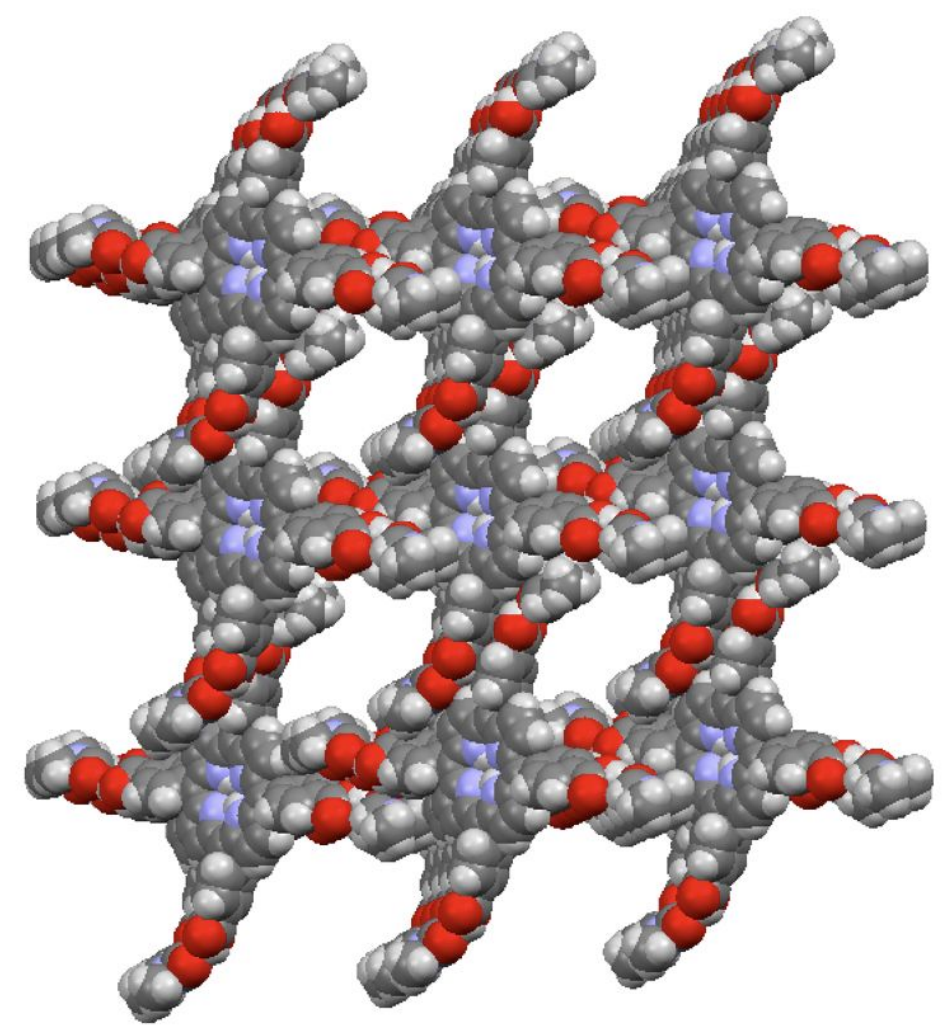

Figure S4 3D porous frameworks of TCPP-4(DMF) with ordered 1D channels in (a) capped sticks and (b) spacefill styles. 
(a)

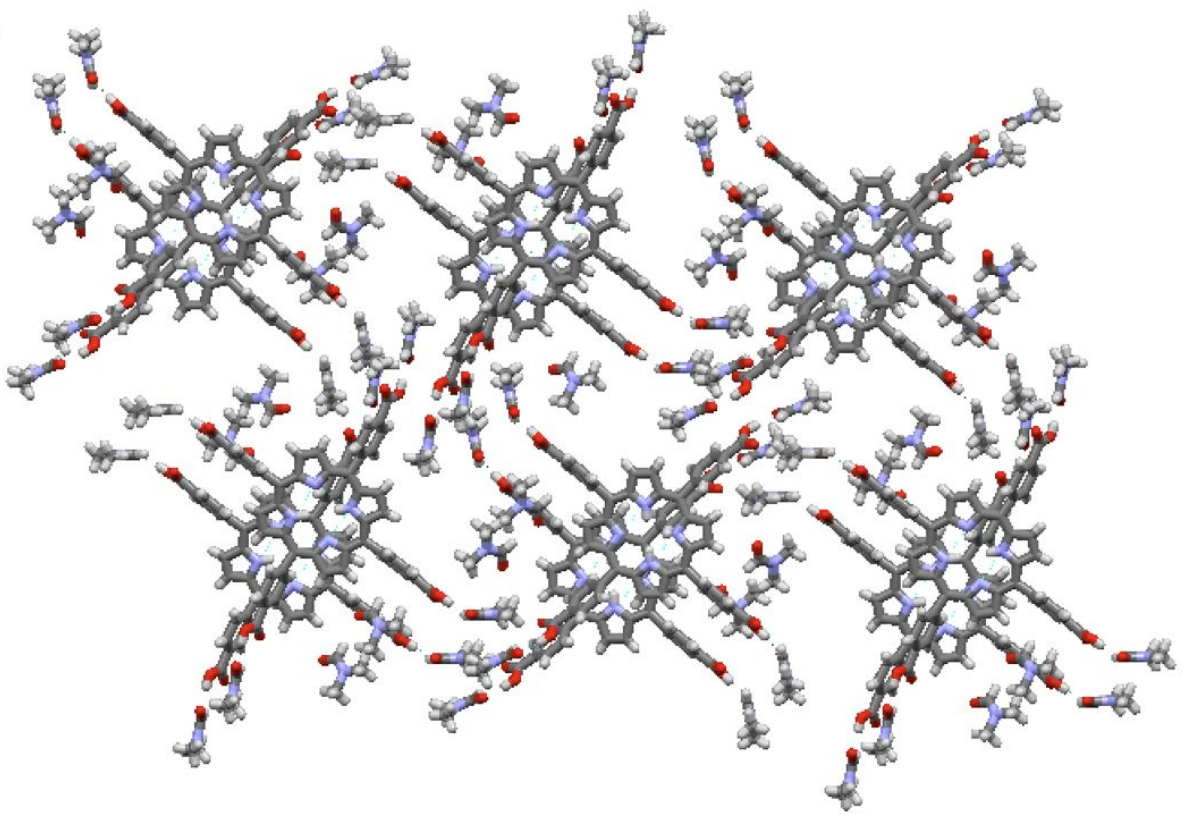

(b)

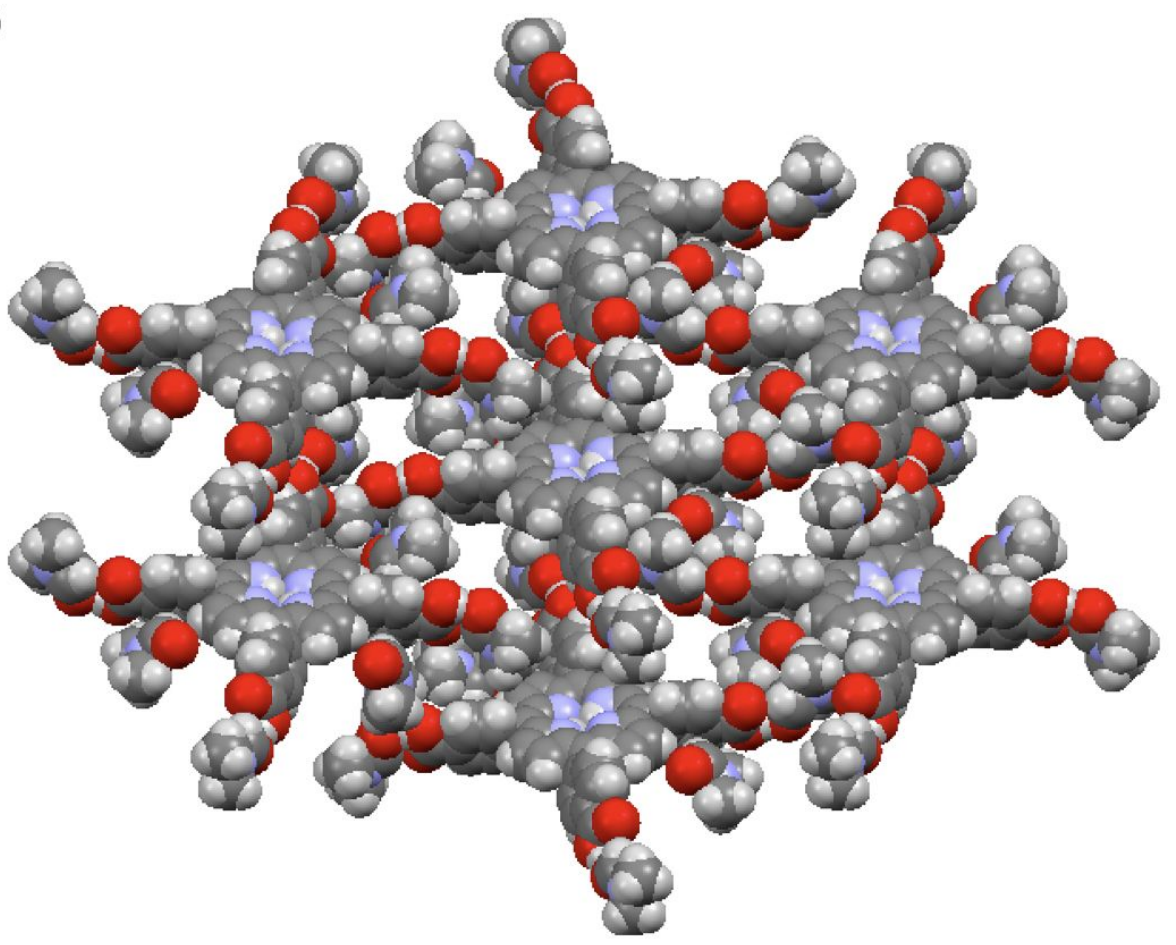

Figure S5 3D stacking styles of TCPP-6(DMF) in (a) capped sticks and (b) spacefill styles. 
Table S2. Percentage contributions (100\%) from individual intermolecular interactions to the Hirshfeld surfaces of the TCPP molecules in HOFs TCPP. 2(DMF), TCPP-4(DMF) and TCPP-6(DMF).

\begin{tabular}{llllll}
\hline HOFs & $\mathrm{H}-\mathrm{H}$ & $\mathrm{N}-\mathrm{H}$ & $\mathrm{O}-\mathrm{H}$ & $\mathrm{C}-\mathrm{H}$ & $\mathrm{C}-\mathrm{C}$ \\
\hline TCPP-2(DMF) & 46.6 & 2.0 & 24.5 & 22.2 & 5.0 \\
TCPP-4(DMF) & 44.0 & 2.8 & 25.0 & 18.0 & 4.0 \\
TCPP-6(DMF) & 42.9 & 3.7 & 29.2 & 18.3 & 3.5 \\
\hline
\end{tabular}

The long distances contacts $(\mathrm{H}-\mathrm{H}, \mathrm{C}-\mathrm{H} \ldots \pi(\mathrm{C}-\mathrm{H}) \mathrm{C}-\mathrm{H}$ and $\pi \ldots \pi(\mathrm{C}-\mathrm{C}))$ was decreased from TCPP-2(DMF), to TCPP-6(DMF), while the closer contacts N$\mathrm{H}$ and $\mathrm{O}-\mathrm{H}$ interactions were increased, suggesting the thermodynamically favored denser structures for TCPP-4(DMF) and TCPP-6(DMF). 


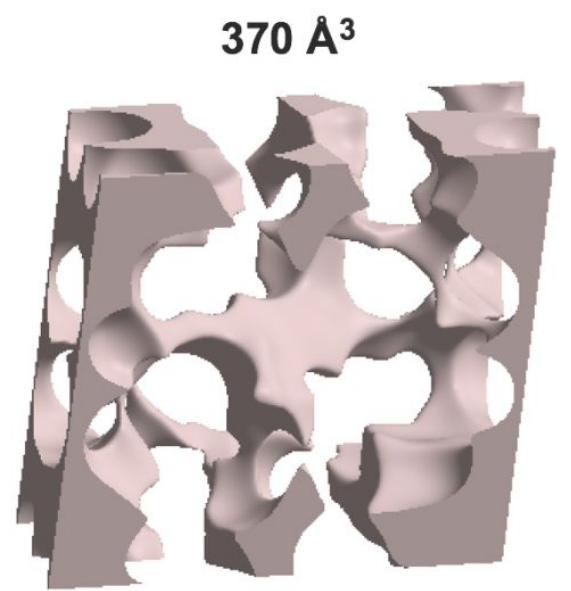

TCPP-2(DMF)
$580 \AA^{3}$

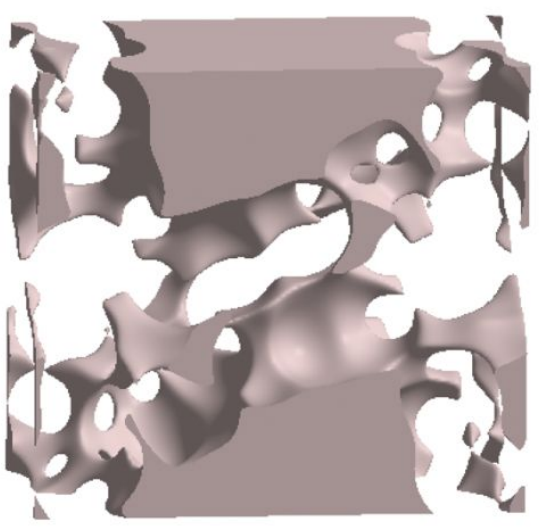

TCPP-4(DMF)

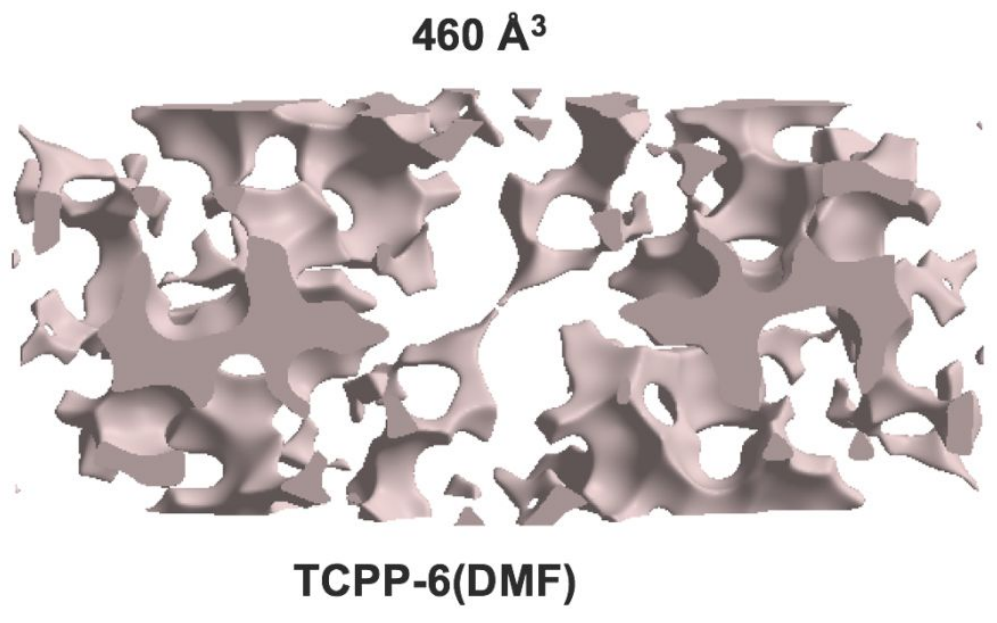

Figure S6 Comparison between the calculated crystal voids of the present three HOFs. 

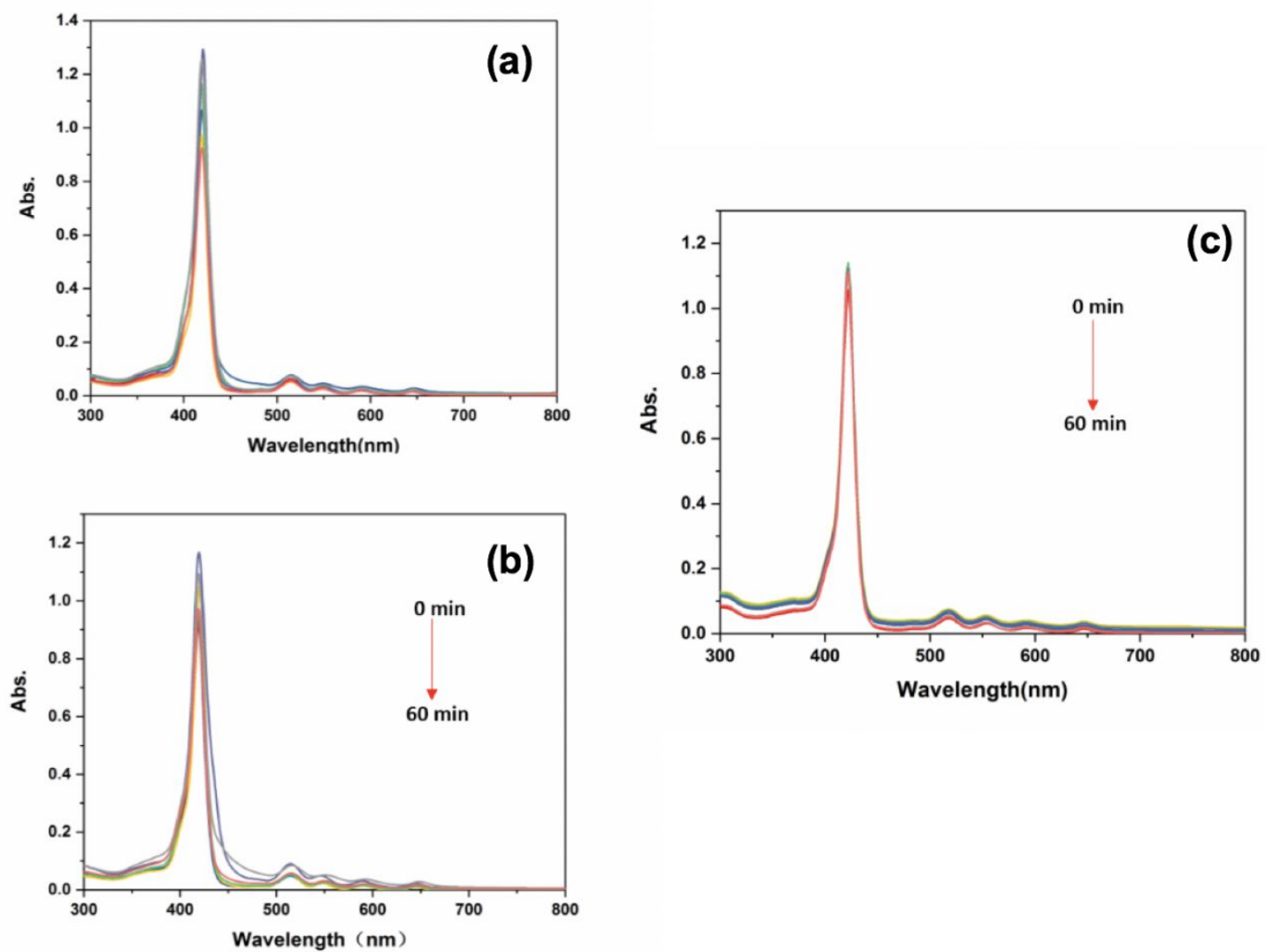

Figure S7 Variation of UV-vis absorbance spectra of TCPP-2(DMF) (a), TCPP4(DMF) (b), TCPP-6(DMF) (c) dispersed in $\mathrm{CH}_{3} \mathrm{CN}$ under irradiation. 

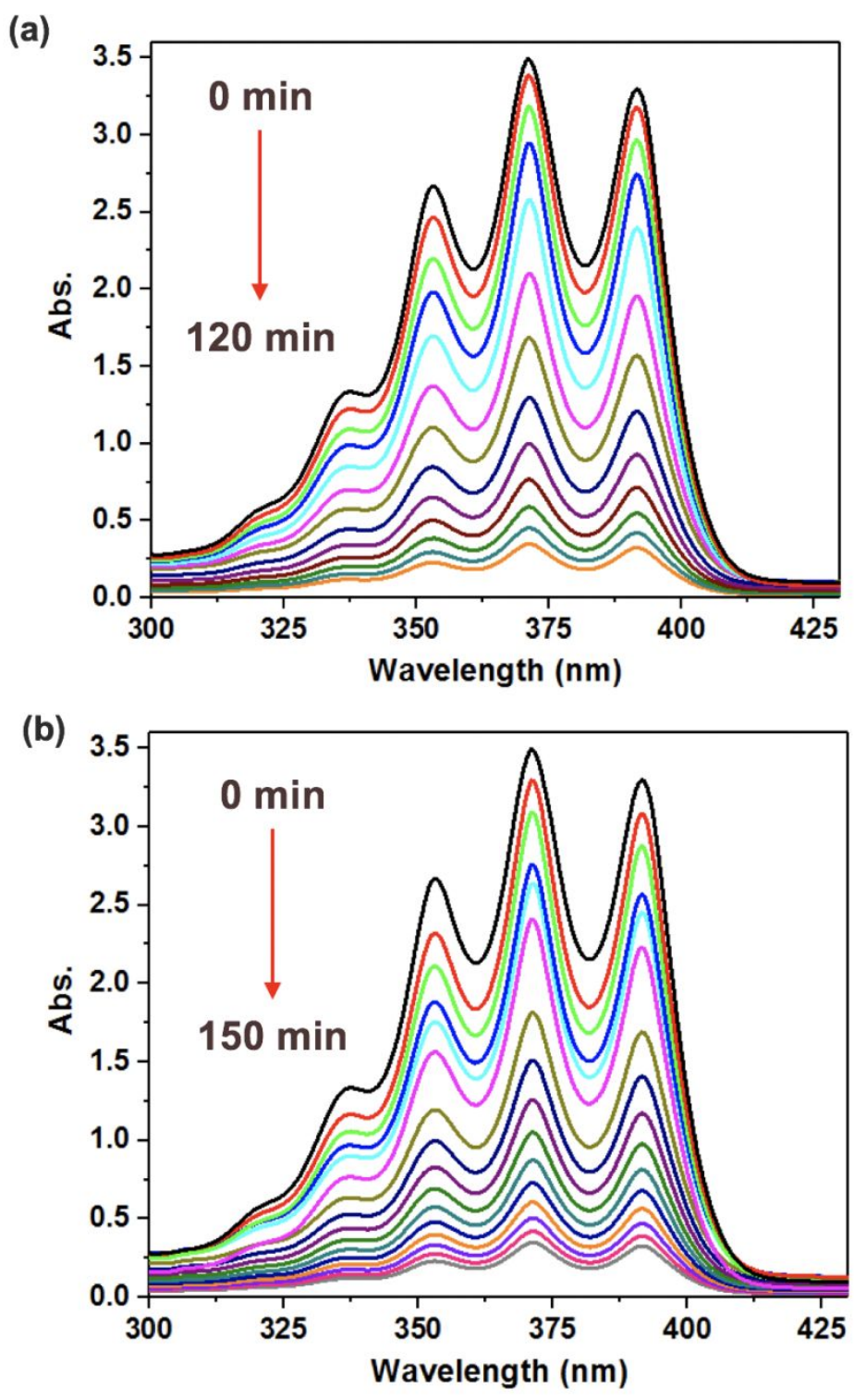

Figure. S8 Variation of the UV-vis spectra of DPA solution with (a) TCPP4(DMF) and (b) TCPP-2(DMF) upon irradiation with 660 nm LED light. 


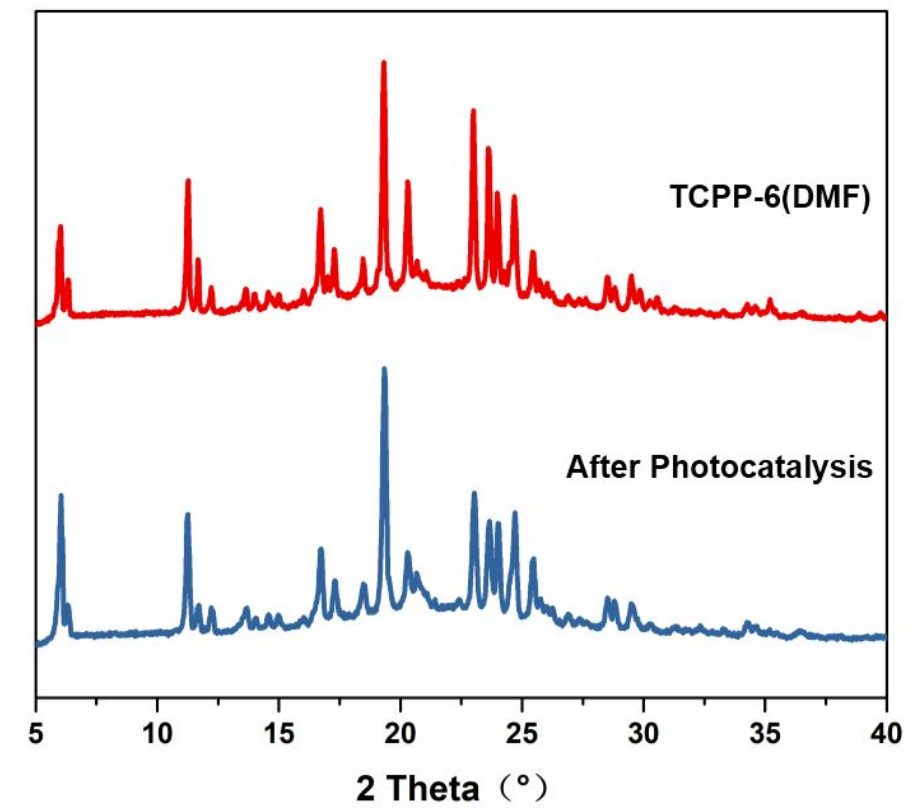

Figure S9 Comparison between the PXRD patterns of TCPP-6(DMF) before and after photocatalysis application. 